\title{
Validation and effect on diabetes control of glycated haemoglobin (HbA1c) point-of-care testing
}

\author{
S Pillay, ${ }^{1} \mathrm{PhD} ; \mathrm{C}$ M Aldous, ${ }^{2} \mathrm{PhD} ;$ D Singh, ${ }^{3} \mathrm{MSc} ;$ D Pillay ${ }^{4}$ \\ ${ }^{1}$ Department of Internal Medicine, Edendale Hospital, Pietermaritzburg, South Africa \\ ${ }^{2}$ School of Clinical Medicine, College of Health Sciences, University of KwaZulu-Natal, Durban, South Africa \\ ${ }^{3}$ Department of Physics, Durban University of Technology, South Africa \\ ${ }^{4}$ Student, Star College, Durban, South Africa
}

Corresponding author: S Pillay (drspillay@iafrica.com)

\begin{abstract}
Background. Optimal control of diabetes mellitus (DM) remains daunting globally. Point-of-care testing (POCT) for glycated haemoglobin (HbAlc) enables the clinician to make immediate management decisions and thereby improve DM control and complications. Better control is increasingly being striven for in developing countries where availability of POCT devices is limited.

Methods. Every alternate patient who visited the diabetes clinic at Edendale Hospital, Durban, South Africa, between 1 June 2017 and 31 August 2017 was invited to participate in the study. These patients made up the POCT group, with the remainder making up the control laboratory group. The POCT group had Quo-Test HbA1c POCT done at the clinic visit and their treatment was adjusted based on the $\mathrm{HbA1c}$ reading, while the control group received standard treatment. The two groups of patients were reviewed at 3 months to identify differences in diabetes control between them.

Results. Data from 266 patients were analysed (135 in the POCT group v. 131 in the control group). There was no significant difference between the price of the POCT and laboratory HbAlc tests $(p=0.823)$. The POCT and laboratory HbAlc values showed good correlation at baseline $(r=0.995 ; p<0.001)$. The two groups of patients were evenly matched in respect of most demographic and clinical variables. Patients in the POCT group showed a significant improvement in mean (standard deviation) glycaemic control between baseline and 3 months ( 9.61 (2.46) v. 8.98 (2.15); $p<0.043)$. No improvement was noted in the control group (9.58 (2.49) v. 9.43 (2.15); $p=0.823)$.

Conclusions. The Quo-Test HbA1c POCT had good correlation with standard laboratory methods in respect of both glycaemic control and price. Patients who had POCT at baseline showed a significant improvement in glycaemic control at 3 months. HbAlc POCT in the setting of a multifaceted approach to diabetes care has been shown to have definite benefits.
\end{abstract}

S Afr Med J 2019;109(2):112-115. DOI:10.7196/SAMJ.2019.v109i2.13447

Point-of-care testing (POCT) for glycated haemoglobin (HbAlc) enables the clinician to make immediate management decisions based on glycaemic control that the patient has achieved over the preceding 3 months. These decisions usually entail both lifestyle and therapeutic modifications. Pillay et al. ${ }^{[1]}$ have shown that the majority of patients with diabetes mellitus (DM) in KwaZulu-Natal Province, South Africa (SA), are diagnosed and have their treatment initiated at local clinic level. Many of these clinics do not have, or have limited access to, HbA1c testing. If testing is available, it often requires a formal venous blood sample to be drawn and sent to a laboratory. Usually the laboratory is not situated on the clinic premises. Patients are then reviewed at a much later date (the delay can range from 1 week to $\geq 6$ months), and only at that stage are decisions made regarding lifestyle and titration of diabetic medications. Suboptimal control of DM has been described in both the public and private healthcare sectors in SA. ${ }^{[2,3]}$ Poor glycaemic control increases the risks of diabetes-related complications. ${ }^{[4]}$ Already poorly controlled patients are at further increased risk of developing these complications while they wait for $\mathrm{HbA1c}$ results.

Tanyanyiwa et al. ${ }^{[5]}$ have previously shown in SA that HbAlc results were comparable to standard laboratory testing when using the DCA Vantage POCT device. ${ }^{[5]}$ Studies are conflicting with regard to whether HbAlc POCT does in fact have a positive impact on overall DM control. Al-Ansary et al. ${ }^{[6]}$ in their meta-analysis found no significant improvement in HbA1c control using HbAlc POCT, although an improvement in patient satisfaction was noted. Other similar studies conducted globally indicate definite improvements in diabetes control in the groups that received HbAlc POCT. ${ }^{[7-11]}$ Laurence et al. ${ }^{[12]}$ found that POCT significantly improved patient satisfaction. Limited data on the benefits on diabetes control of HbA1c POCT exist in SA. Mash et al. ${ }^{[13]}$ suggested in their report on a study conducted in the Western Cape Province that the effects of HbAlc POCT should not be evaluated in isolation but rather in combination with strategies to improve clinician inertia, coupled with stronger primary healthcare. ${ }^{[13]}$ A multifaceted approach to diabetes care was introduced at the diabetes clinic at Edendale Hospital (EDH), Pietermaritzburg, KwaZulu-Natal, in 2012. ${ }^{[14]}$ Improved clinician and nurse education on diabetes, based on the Society for Endocrinology, Metabolism and Diabetes of South Africa (SEMDSA) guidelines, was integral to this approach.

\section{Objectives}

To provide data from SA on the efficacy of using HbAlc POCT in a diabetes clinic, and to determine whether there was a positive correlation between POCT HbAlc readings and formal laboratory $\mathrm{HbA} 1 \mathrm{c}$ readings.

\section{Methods}

This was a quantitative, interventional quasi-experimental study conducted in the diabetes clinic at $\mathrm{EDH}$, a regional-level hospital. 
Every alternate patient who presented to the clinic over a 3-month period (from 1 June 2017 up to and including 31 August 2017) was offered the opportunity to participate in the study. If they accepted this invitation, they signed a form giving informed consent to participate. If they refused, their diabetes was managed as per the normal clinic schedule. Patients who had given informed consent (the POCT group) then had their POCT of HbAlc performed as part of the normal vital clinical signs. The only difference between the two groups was that the POCT group had POCT HbAlc testing done in addition to the normal vital clinical signs performed by nursing staff. Clinicians working in the diabetes clinic made active management decisions in respect of lifestyle modification and intensification of pharmacological therapy based on the POCT HbAlc readings. The patients who were not recruited into the study (the control group) received their routine diabetes management. Both groups of patients (control and POCT) had formal venous blood samples drawn. These were sent to the National Health Laboratory Service (NHLS), where the Bio-Rad D-10 machine (Bio-Rad Laboratories, USA) was used to obtain HbAlc values. The machine is National Glycohemoglobin Standardisation Program accredited to ensure standardisation of $\mathrm{HbAlc}$ results.

Both the control and POCT groups of patients were then seen after 3 months and the same process was followed. Since September 2012, all consultations at the EDH diabetes clinic have been done in a structured and comprehensive manner using specially designed datasheets that are completed for every patient seen at the clinic and have been approved for use by the University of KwaZulu-Natal Biomedical Research and Ethics Committee (ref. no. 194/95). The datasheets are completed in triplicate. One copy of the datasheet is given to the patient to take to their local clinic, the second is affixed to the patient's outpatient file, and the third is kept in the clinic. This third copy was used as a source document for all the clinical and biochemical variables required for completion of this study.

\section{Measurements}

POCT was performed using a Quo-Test HbAlc analyser (EKF Diagnostics, UK). Reagents were appropriately stored in a refrigerator as prescribed by the manufacturer. A finger-prick test is usually performed on all patients attending the clinic for random blood glucose testing. A second drop of capillary blood from the same finger-prick was used for the Quo-Test analyser. HbA1c analysis was completed by the machine within 4 minutes. This POCT HbAlc reading was entered onto the patient's datasheet. Both groups of patients had all their vital clinical signs performed by the nursing staff. These included urine dipstick findings, sitting and standing blood pressures $(\mathrm{mmHg})$, resting heart rate (beats per minute), height $(\mathrm{cm})$, weight $(\mathrm{cm})$, waist circumference $(\mathrm{cm})$, body mass index $\left(\mathrm{BMI}, \mathrm{kg} / \mathrm{m}^{2}\right)$ and random glucose measurement $(\mathrm{mmol} / \mathrm{L})$ using an Accu-Chek glucometer (Roche, Switzerland). Both the POCT and control groups of patients had baseline and 3-month venous blood samples drawn. These samples were sent to the NHLS for HbAlc measurement, a lipogram and renal function tests including the glomerular filtration rate.

\section{Data collection and statistical analysis}

Continuous variables were documented as mean (standard deviation) values. Numbers and percentages were expressed for categorical variables. Numerical data were compared using analysis of variance, while categorical data relationships were determined using either the $\chi^{2}$ or Fisher's exact tests. A $p$-value $<0.05$ was used as indicator of significance. Pearson's correlation was used to measure the strength of the linear association between POCT HbAlc and laboratory HbAlc testing. Data were analysed using the Statistical Package for Social Science (SPSS) version 25 for Windows (SPSS Inc., USA).

\section{Ethical considerations}

All patients included in the study signed an informed consent form available in both English and isiZulu. All patients were allocated a study-specific number to maintain anonymisation of data. The data were stored on a password-protected computer.

Ethics approval for this study was obtained from the University of KwaZulu-Natal Biomedical Research and Ethics Committee (ref. no. BE 491/16).

\section{Results}

The POCT and control groups consisted of 135 and 131 patients, respectively. Data from a total of 266 patients were analysed for the study. There was no significant difference between the cost of the Quo-Test HbA1c POCT and the NHLS HbAlc test (ZAR91.20 v. ZAR87.78, respectively; $p=0.823$ ).

Table 1 provides the demographics and baseline data for both groups. Other than for BMI in males, no statistical differences were noted between the two groups for the variables listed in Table 1.

Fig. 1 demonstrates that the Quo-Test POCT and laboratory HbA1c values showed good correlation at baseline $(r=0.995 ; p<0.001)$.

Table 2 shows that there was no statistical difference between mean $\mathrm{HbAlc}$ levels in the POCT group and the laboratory group, both at baseline and at the 3-month visit.

Table 3 and Figs 2 and 3 demonstrate that a significant improvement in glycaemic control was noted in the POCT group, while in the control group no statistically significant difference could be shown between baseline and 3 months.

\section{Discussion}

Optimal control of DM remains a problem worldwide. Improved diabetes control will ease the burden that the complications of DM place on patients and national health budgets. POCT of HbAlc has been shown globally to improve overall diabetes control and by inference diabetes-related complications. ${ }^{[7-11]}$

So far, limited studies have been conducted in SA to determine whether HbA1c POCT has benefits similar to those documented elsewhere. In the report on their study in the Western Cape, Mash et al. ${ }^{[13]}$ suggested that POCT for HbAlc showed no benefits in improving glycaemic control in public sector primary care practice. They further commented that POCT should be re-evaluated in the context of an improved multifaceted approach targeting both the

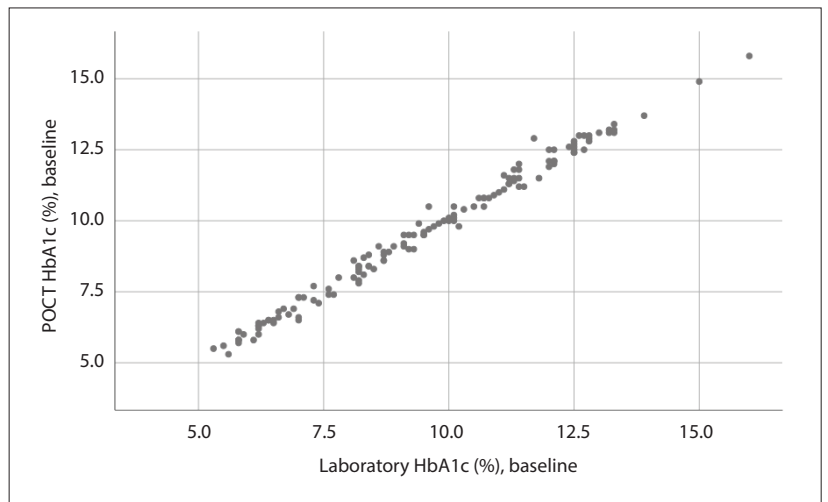

Fig. 1. Correlation between POCT and laboratory HbA1c values. (POCT $=$ point-of-care testing; HbAlc = glycated haemoglobin). 
Table 1. Demographics of the patient population

\begin{tabular}{|c|c|c|c|}
\hline & Baseline POCT group & Baseline control group & $p$-value \\
\hline Patients, $n$ & 135 & 131 & \\
\hline Male & 45 & 43 & 0.896 \\
\hline Female & 90 & 88 & 0.896 \\
\hline Age (years), mean (SD) & $53.6(15.6)$ & $53.7(16.9)$ & 0.875 \\
\hline Male & $48.5(17.8)$ & $49.5(18.6)$ & 0.776 \\
\hline Female & $56.2(13.7)$ & $55.7(15.6)$ & 0.990 \\
\hline \multicolumn{4}{|l|}{ Type of DM } \\
\hline Type 1 & 17 & 24 & 0.308 \\
\hline Type 2 & 116 & 109 & 0.308 \\
\hline Duration of DM (years), mean (SD) & $9.5(9.3)$ & $8.8(7.8)$ & 0.784 \\
\hline \multicolumn{4}{|l|}{ Patients with coexisting illnesses, $n$} \\
\hline Hypertension & 90 & 94 & 0.691 \\
\hline Chronic kidney disease & 21 & 19 & 0.864 \\
\hline HIV infection & 27 & 21 & 0.426 \\
\hline Duration of HIV infection (years), mean (SD) & $6.1(4.6)$ & $7.3(4.8)$ & 0.394 \\
\hline Patients on antiretrovirals, $n$ & 20 & 19 & 0.356 \\
\hline Years on ARVs, mean (SD) & $4.5(1.4)$ & $4.6(1.2)$ & 0.279 \\
\hline \multicolumn{4}{|l|}{ Patients with substance use, $n$} \\
\hline Smoker & 8 & 8 & 1.000 \\
\hline Consumed alcohol & 11 & 5 & 0.196 \\
\hline BMI $\left(\mathrm{kg} / \mathrm{m}^{2}\right)$, mean $(\mathrm{SD})$ & $32.1(8.7)$ & $32.1(7.6)$ & 0.812 \\
\hline Male & $26.5(5.7)$ & $29.5(7.4)$ & 0.033 \\
\hline Female & $35.1(8.5)$ & $33.5(7.3)$ & 0.161 \\
\hline Waist circumference $(\mathrm{cm})$, mean $(\mathrm{SD})$ & $108.3(18.3)$ & $109.1(17.0)$ & 0.638 \\
\hline Male & $95.8(14.6)$ & $101.6(17.5)$ & 0.088 \\
\hline Female & $115.0(16.5)$ & $112.9(15.4)$ & 0.413 \\
\hline HbAlc (\%), mean (SD) & $9.6(2.4)$ & $9.5(2.5)$ & 0.819 \\
\hline \multicolumn{4}{|l|}{ Blood pressure $(\mathrm{mmHg})$, mean $(\mathrm{SD})$} \\
\hline Systolic & $138.7(28.1)$ & $146.6(26.5)$ & 0.014 \\
\hline Diastolic & $82.4(14.0)$ & $85.6(13.6)$ & 0.104 \\
\hline Total cholesterol (mmol/L), mean (SD) & $4.5(1.4)$ & $4.6(1.2)$ & 0.279 \\
\hline LDL cholesterol (mmol/L), mean (SD) & $2.4(1.2)$ & $2.5(1.0)$ & 0.533 \\
\hline Creatinine (mmol/L), mean (SD) & $94.5(48.3)$ & $94.3(53.0)$ & 0.467 \\
\hline
\end{tabular}

Table 2. Mean HbA1c levels in the in POCT and laboratory groups

\begin{tabular}{|c|c|c|c|}
\hline \multirow[b]{2}{*}{ Time } & \multicolumn{2}{|c|}{ HbAlc (\%), mean (SD) } & \multirow[b]{2}{*}{$p$-value ${ }^{x}$} \\
\hline & POCT group & Control group & \\
\hline Baseline & $9.61(2.46)$ & $9.58(2.49)$ & 0.793 \\
\hline 3 months & $8.98(2.15)$ & $9.43(2.15)$ & 0.071 \\
\hline
\end{tabular}

clinician and the primary healthcare setting. A multifaceted approach of this nature was introduced into the diabetes clinic at EDH in $2012,{ }^{[14]}$ to which clinician and nurse re-education on the management of DM as prescribed by the local SA guidelines was integral. The EDH diabetes clinic therefore provided an excellent setting to investigate the effects of HbAlc POCT on diabetes control in the context of an already established multifaceted approach. Not surprisingly, we demonstrated that patients who received HbAlc POCT testing and intensification of therapy (lifestyle and therapeutic) at baseline had significant improvements in glycaemic control at 3 months compared with the laboratory control group.
Recently, Abbai et al. ${ }^{[15]}$ demonstrated in their study in Durban, $\mathrm{SA}$, that there was good correlation between POCT and laboratory HbAlc values using the Afinion AS100 point-of-care analyser. This study, however, only included patients aged $>50$ years (mean 66 years). Tanyanyiwa et al..$^{[5]}$ have previously shown in SA that $\mathrm{HbAlc}$ results were comparable to standard laboratory testing when using the DCA Vantage POCT device. ${ }^{[5]}$ In both these studies, no follow-up of patients was performed to assess the effects of POCT on diabetes control at a later stage. ${ }^{[5,15]}$ Our study showed good correlation between the Quo-Test POCT HbAlc values and NHLS laboratory values. Pillay et al. ${ }^{[1]}$ showed that the majority of patients with diabetes are diagnosed and have their therapy initiated at their local healthcare clinic. HbA1c POCT is often not available at resource-limited clinics, so formal venous bloods have to be drawn and sent to a laboratory, which may not be situated on the premises. The $\mathrm{HbAlc}$ results are then only reviewed at the patient's next clinic visit in $1-6$ months' time, and only at this visit will therapy be modified. Introduction of HbA1c POCT at these clinics would provide an excellent avenue to improve overall diabetes control and thereby decrease diabetes-related complications. In addition to improved diabetes control, availability of point-of-care 
Table 3. Changes in HbAlc between baseline and 3 months in the POCT and control groups

\begin{tabular}{|c|c|c|c|c|c|c|}
\hline & \multicolumn{2}{|c|}{ POCT group } & \multirow[b]{2}{*}{$p$-value ${ }^{*}$} & \multicolumn{2}{|c|}{ Control group } & \multirow[b]{2}{*}{$p$-value ${ }^{*}$} \\
\hline & Baseline & 3 months & & Baseline & 3 months & \\
\hline HbAlc (\%), mean (SD) & $9.61(2.46)$ & $8.98(2.15)$ & 0.043 & $9.58(2.49)$ & $9.43(2.15)$ & 0.823 \\
\hline
\end{tabular}

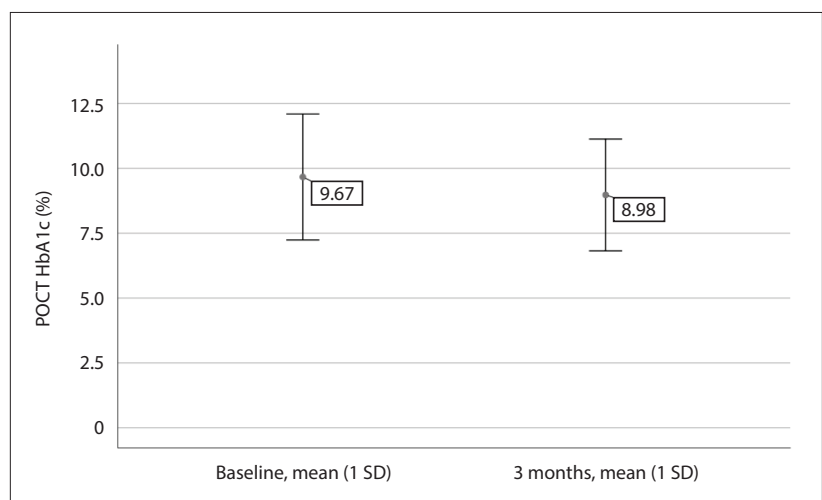

Fig. 2. Significant improvement in HbAlc in the POCT group. $(P O C T=$ point-of-care testing; HbAlc = glycated haemoglobin; $S D=$ standard deviation.)

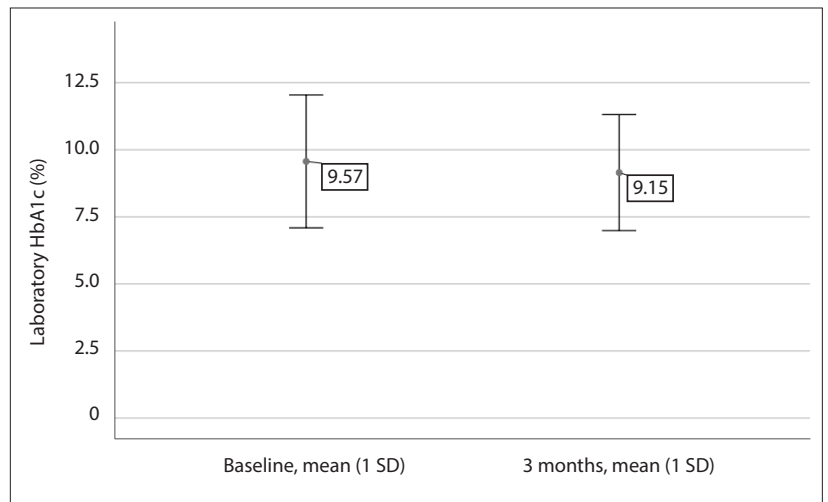

Fig. 3. No significant difference in HbAlc in the control group. (HbAlc $=$ glycated haemoglobin; $S D=$ standard deviation.)

devices at these clinics would help to improve patient satisfaction and compliance.

\section{Study limitations}

The follow-up period for this study was only 3 months. It is suggested that future prospective studies have a longer follow-up period to establish whether improvements as were observed in this study persist.

\section{Conclusions}

This study showed that POCT of HbAlc with the Quo-Test device showed good correlation with laboratory values and that the cost was statistically no different to the current NHLS prices. Patients who received POCT for HbAlc showed a significant improvement in diabetes control after a 3-month period. These findings augur well for the roll-out of these devices in local healthcare facilities.

Declaration. None.

Acknowledgements. None.

Author contributions. The principal author SP and DP made substantial contributions to conception and design of the work, collection of all data, interpretation and performing statistical analyses of the data and writing of the paper and final approval, and agree to be accountable for all aspects of the research. CMA made substantial contributions to critically reviewing and editing the draft paper and final approval, and agrees to be accountable for all aspects of the research. DS made substantial contributions to performing statistical analysis on study data, and agrees to be accountable for all aspects of the research.

Funding. None.

Conflicts of interest. None.

1. Pillay S, Lutge E, Aldous C. The burden of diabetes mellitus in KwaZulu-Natal's public sector: A 5-year perspective. S Afr Med J 2016;106(4):384-388. https://doi.org/10.7196/SAMJ.2016.v106i4.9920

2. Pillay S, Aldous C, Mahomed F. Diabetic patients served at a regional level hospital: What is their clinical picture? J Endocrinol Metab Diabetes S Afr 2015;20(1):60-66. https://doi.org/10.1080/16089 677.2015.1030856

3. Amod A, Riback W. Diabetes guidelines and clinical practice: Is there a gap? The South African Cohort of the International Diabetes Management Practices Study. J Endocrinol Metab Diabetes S Afr 2012;17(2):85-90. https://doi.org/10.1080.22201009.2012.10872282

4. American Diabetes Association. Implications of the United Kingdom Prospective Diabetes Study. Diabetes Care 2002;25(1):S28-S32. https://doi.org/10.2337/diacare.25.2007.S28

5. Tanyanyiwa D, Dandara C, Bhana SA, et al. Implementation of POCT in the diabetic clinic in a large hospital. Afr Health Sci 2015;15(3):902-907. https://doi.org/10.4314/ahs.v15i3.26

6. Al-Ansary L, Farmer A, Hirst J, et al. Point-of-care testing for $\mathrm{HbAlc}$ in the management of diabetes: A systematic review and metaanalysis. Clin Chem 2011;57(4):568-576. https://doi.org/10.1373/ clinchem.2010.157586

7. Grieve R, Beech R, Vincent J, Mazurkiewicz J. Near patient testing in diabetes clinics: Appraising the costs and outcomes. Health Technol Assess 1999;3(15):1-74. https://doi.org/10.3310.hta3150

8. Ferenczi A, Reddy K, Lorber DL. Effect of immediate hemoglobin Alc results on treatment decisions in office practice. Endocr Pract 2001; 7(2):85-88. https://doi.org/10.4158/EP.7.2.85

9. Peterson JR, Finley JB, Okorodudu AO, et al. Effect of point-of-care on maintenance of glycaemic control as measured by Alc. Diabetes Care 2007;30(3):713-715. https://doi.org/10.2337/dc06-1909

10. Rust G, Gailor M, Daniels E, McMillan-Persaud B, Strothers H, Mayberry R. Point of care Rust G, Gailor M, Daniels E, McMillan-Persaud B, Strothers H, Mayberry R. Point of care
testing to improve glycaemic control. Int J Health Care Assur 2008:21(3):325-335. https://doi. testing to improve glycaemic co

11. Cagliero E, Levina EV, Nathan DM. Immediate feedback of HbAlc levels improves glycemic control in type 1 and insulin-treated type 2 diabetic patients. Diabetes Care 1999;22(11):1785-1789. https://doi.
the org/10.2337/diacare.22.11.178

12. Laurence CO, Gialamas A, Bubner T, et al. Patient satisfaction with point-of-care testing in general practice. Br J Gen Pract 2010;60(572):e98-e104. https://doi.org/10.3399/bjgp10X483508

13. Mash R, Ugoagwu A, Rensburg M, Erasmus R. Evaluating point-of-care testing for glycosylated haemoglobin in public sector primary care facilities in the Western Cape, South Africa. S Afr Med J 2016;106(12):1236-1240. https://doi.org/10.7196/SAMJ.v106i12.10728

14. Pillay S, Aldous C. Introducing a multifaceted approach to the management of diabetes mellitus in resource-limited settings. S Afr Med J 2016;106(5):456-458. https://doi.org/10.7196/ SAMJ.2016v106i5.10409

15. Abbai NS, Nyirenda M, Reddy T, Ramjee G. Good correlation between the Afinion AS100 analyser and the ABX Pentra 400 analyser for the measurement of glycosylated haemoglobin and lipid levels in older adults in Durban, South Africa. S Afr Med J 2018;108(1):50-55. https://doi.org/10.7196/SAMJ.2018. v108i1.12548

Accepted 16 July 2018 